\title{
Genetic polymorphism and gene expression of microsomal epoxide hydrolase in non-small cell lung cancer
}

\author{
TORNG-SEN LIN ${ }^{1}$, HSUAN-HUA HUANG ${ }^{2}$, YI-HSIN FAN ${ }^{3}$, SHIOW-HER CHIOU ${ }^{3}$ and KUAN-CHIH CHOW ${ }^{4}$ \\ ${ }^{1}$ Chang-Hua Christian Hospital, Department of Surgery, Chang-Hua; ${ }^{2}$ Feng-Yuan Hospital, \\ Department of Health, Feng-Yuan; ${ }^{3}$ Graduate Institute of Veterinary Microbiology; \\ ${ }^{4}$ Institute of Biomedical Sciences, National Chung Hsing University, Taichung, Taiwan, R.O.C.
}

Received November 15, 2006; Accepted December 27, 2006

\begin{abstract}
Genetic polymorphisms of microsomal epoxide hydrolase $(\mathrm{mEH})$ have been associated with increased risk of lung cancer. However, expression of $\mathrm{mEH}$ and its clinical significance in non-small cell lung cancer (NSCLC) have not been investigated. In this study we investigated the expression and genetic polymorphism of $\mathrm{mEH}$ in non-small cell lung cancer (NSCLC) patients. Genetic polymorphism was determined by restriction fragment length polymorphism of polymerase chain reaction (PCR) products. The allelic expression pattern as well as expression level of $\mathrm{mEH}$ were determined by reverse transcription-PCR (RT-PCR), cDNA sequencing, sequence alignment, immunoblotting and immunohistochemistry. Genotype distributions of $\mathrm{mEH}$ in Taiwan's NSCLC patients were $44.4 \%$ of ${ }^{340} \mathrm{TAC} /{ }^{340} \mathrm{TAC}$, $48.6 \%$ of ${ }^{340} \mathrm{TAC} /{ }^{340} \mathrm{CAC}$, and $7.0 \%$ of ${ }^{340} \mathrm{CAC} /{ }^{340} \mathrm{CAC}$ in exon 3 , and $80.6 \%$ of ${ }^{418} \mathrm{CAT} /{ }^{418} \mathrm{CAT}, 19.4 \%$ of ${ }^{418} \mathrm{CAT} /{ }^{418} \mathrm{CGT}$ and $0 \%$ of ${ }^{418} \mathrm{CGT} /{ }^{418} \mathrm{CGT}$ in exon 4 . Of the $72 \mathrm{NSCLC}$ biopsies analyzed, $\mathrm{mEH}$ was expressed in $60(83 \%)$ surgical specimens, and the major allelic expression pattern was fast type (Tyr113) in exon 3 (90.3\%) and slow type (His139) in exon $4(100 \%)$. Immunohistochemical staining showed that $\mathrm{mEH}$ was expressed in 326 of $423(77.0 \%$ ) tumor (lung tissue) specimens and in 48 of $93(51.6 \%)$ metastatic lymph nodes. A significant difference in patient survival was found when $\mathrm{mEH}$ expression and adriamycin-containing chemotherapy were used to group patients $(\mathrm{p}=0.0167)$. In conclusion, with the combination of fast type (Tyr113) and slow type
\end{abstract}

Correspondence to: Dr K.-C. Chow, Institute of Biomedical Sciences, National Chung Hsing University, 250 Kuo Kuang Road, Taichung 40227, Taiwan, R.O.C.

E-mail:kcchow@dragon.nchu.edu.tw

Dr S.-H. Chiou, Graduate Institute of Veterinary Microbiology, National Chung Hsing University, 250 Kuo Kuang Road, Taichung 40227, Taiwan, R.O.C.

E-mail: shchiou@dragon.nchu.edu.tw

Key words: microsomal epoxide hydrolase, non-small cell lung cancer, genetic polymorphism, allelic expression pattern, cigarette smoking, drug resistance
(His139), the mEH enzyme expressed in most NSCLC patients may have intermediate activity. Our findings indicate that with respect to cancer risk and disease progression, the expression level of $\mathrm{mEH}$ is as important as genetic polymorphism. In addition, mEH expression in NSCLC could be involved in drug resistance and prognosis of patients.

\section{Introduction}

Epoxide hydrolase (EH) is a phase I biotransformation enzyme that catabolizes epoxides, which are converted from hydrophorbic polycyclic aromatic hydrocarbons (PAH), into dihydrodiols (1-3). In contrast to highly reactive epoxides, dihydrodiols are mostly inert and can be excreted after conjugating to glutathione (4). However, EH may not always be protective. Hydrolysis of certain epoxides by EH may result in carcinogenic metabolites that can inauspiciously form DNA adducts (1).

$\mathrm{EH}$ is most abundant in liver and kidney (5). Soluble and microsomal are two forms of EH which have been detected $(6,7)$. Among them, microsomal epoxide hydrolase $(\mathrm{mEH}$, EC 3.3.2.3) has been more broadly studied. The enzyme is encoded by a single gene (EPHX1) in chromosome 1p11-qter. Two polymorphic sites have been reported within the coding region of EPHX1. One is located in exon 3 at amino acid residue 113 , in which tyrosine (Tyr113, TAC) or histidine (His113, CAC) is expressed, and the other is located in exon 4 at amino acid residue 139, in which histidine (His139) or arginine (Arg139) is expressed $(1,8,9)$. The enzyme with Tyr 113 (fast type) has $50 \%$ higher activity than that with His 113 (slow type), whereas mEH with His139 (slow type) has only 25\% activity of that with $\operatorname{Arg} 139$ (fast type) (8). Previous studies indicate that the mEH enzyme with Tyr 113 (fast type) is closely associated with the increased risk of lung, breast, laryngeal and colon cancers (10-15). In particular, when patients with higher $\mathrm{mEH}$ activity (fast type) were exposed frequently to tobacco smoking, cancer risk increased significantly $(16,17)$. In addition, $\mathrm{mEH}$ is further suggested to have a role in suppressing tamoxifen response and causing poor prognosis in patients with primary breast cancer $(12,18)$.

Several molecular methods, including restriction fragment length polymorphism (RFLP), single-stranded conformation polymorphism (SSCP), and polymerase chain reaction (PCR) followed by direct DNA sequencing, have been used to detect 
genetic polymorphisms $(11,19,20)$. Although data from epidemiological screening and extensive statistical analysis have indicated that certain allelic polymorphism is indeed correlated with higher risk of cancer, the allelic expression pattern and expression level of $\mathrm{mEH}$, which may actually determine the predisposition of tumor development and possibly disease progression, on the other hand, have not been intensively investigated.

In this report, we used reverse transcription-polymerase chain reaction (RT-PCR) to assess expression of $\mathrm{mEH}$ mRNA, and to obtain mEH cDNA. Subsequently, allelic variants of $\mathrm{mEH}$ were determined by cDNA nucleotide sequencing. Moreover, we used an immunohistochemical method to detect $\mathrm{mEH}$ expression in surgical specimens of NSCLC, and $\mathrm{mEH}$ expression was confirmed by immunoblotting. Correlation between clinicopathological parameters and $\mathrm{mEH}$ expression as well as the prognostic significance of $\mathrm{mEH}$ in NSCLC patients were evaluated statistically.

\section{Materials and methods}

Patients and tissue samples. From September 1986 to September 2001, samples were collected from 452 patients who had been diagnosed as NSCLC. Stages of the disease were classified according to the new international staging system for lung cancer. The Medical Ethics Committee approved the protocol, and written informed consent was obtained from every patient before surgery. All patients had undergone surgical resection and radical N2 lymph node dissection. Tumor size, lymph node number, differentiation, vascular invasion and mitotic number were also evaluated. Patients with lymph node involvement and patients with locoregional recurrence received irradiation at the afflicted areas. Those with distant metastasis were treated with chemotherapy (21). After treatment, patients were routinely followed every 3 to 6 months as outpatients. Tumor recurrence and metastasis were identified when blood examination, biochemical studies, chest radiography, abdominal sonography, whole body bone scan and computerized tomography scans of chest showed any suspected evidence of the disease.

RNA extraction and reverse transcription-polymerase chain reaction. Total RNA was isolated from lung cancer tissue by using a SNAP RNA column (Invitrogen, San Diego, CA). After measurement of RNA yield, cDNA was synthesized by random primers and AMV reverse transcriptase. An aliquot of cDNA was then subjected to 35 cycles of PCR. The reaction mixture contained 1X Taq buffer (BRL, Bethesda, MD), $1.5 \mathrm{mM} \mathrm{MgCl}_{2}, 2 \mu \mathrm{M}$ dNTP, $0.25 \mu \mathrm{M}$ of respective $3^{\prime}$ and 5' primers, $1 \mathrm{U}$ of Taq DNA polymerase, and $2 \mu 1$ of cDNA. PCR was carried out in a standard procedure: denaturing at $94^{\circ} \mathrm{C}$ for $30 \mathrm{sec}$, hybridizing at $52^{\circ} \mathrm{C}$ for $45 \mathrm{sec}$, and elongating at $72^{\circ} \mathrm{C}$ for $2 \mathrm{~min}$. The primer sequences for $\mathrm{mEH}$ were 5'-CATGTGGCTAGAAATCCTCC-3' (sense) and 5'-TCAT TGCCGCTCCAGCACCGACA-3' (antisense). The amplified products were analyzed in $1 \%$ agarose gel, and visualized by ethidium bromide staining. The mEH fragment was 1369 base pairs (bp). The cDNA was inserted into plasmid pCRII and a DNA sequence of five selected clones as well as PCR products were determined by an automatic DNA sequencer (ABI
PRISM, Perkin-Elmer Applied Biosystems, Foster City, CA, USA). Following alignment of the reading frame (http:// www.ncbi.nlm.nih.gov/entrez, NM_000120), amino acid sequence in the $\mathrm{mEH}$ coding region was determined for the individual specimen.

Immunoblotting and immunological staining. The procedure for immunoblotting has been described previously (22). Briefly, proteins were separated in a $10 \%$ SDS-polyacrylamide gel with $4.5 \%$ stacking gel. After electrophoresis, proteins were transferred to a nitrocellulose membrane. The membrane was then incubated with $\mathrm{mEH}$ specific antibodies (Union Biotech, Inc., Taipei, Taiwan, R.O.C.). The signal was amplified by biotin-labeled goat anti-mouse IgG, and peroxidase-conjugated streptavidin. The protein was visualized by exposing the membrane to an ECL film (Amersham, Buckinghamshire, UK) with enhanced chemiluminescent reagent (Pierce, Rockford, IL, USA). The same antibodies were used for immunohistochemical staining, which was performed by an immunoperoxidase method as previously described (23).

Slide evaluation. In each case, normal lung tissue served as the internal negative control. Slides were read by two independent pathologists without prior clinicopathological knowledge. A specimen was considered positive if more than $10 \%$ of cancer cells were positively stained and negative if less than $10 \%$ were positively stained (23).

Genotype and haplotype analyses of $m E H$. To examine exon 3, primer sequences were 5'-GATCGATAAGTTCCGTTTC ACC-3' (sense); and 5'-ATCCTTAGTCTTGAAGTGAG GAT-3' (antisense). The amplified products were treated with $E c o \mathrm{R} \mathrm{V}$, and resolved in a $3 \%$ agarose gel. The homozygous allele of His113 was identified if a 162-bp fragment appeared. If a 140-bp band appeared, the patient was identified as having homozygous Tyr113 allele, and if both 162-bp and140-bp fragments appeared, the patient was identified as heterozygous with His113/Tyr113. Although a 22-bp DNA fragment was expected in Tyr113 allele following EcoR V digestion, the primers frequently obscured the fragment. For exon 4, primers were 5'-GGGGTGCCAGAGCCTGACCGT-3' and 5'-AACACCGGGCCCACCCTTGGC-3'. The amplified products were digested with $R s a$ I before resolving in a $3 \%$ agarose gel. When 295- and 62-bp fragments appeared, the patient had homozygous allele of His139. When 174-, 121and 62-bp bands appeared, the patient was identified as homozygous Arg139 allele, and when all four DNA fragments appeared, the patient was heterozygous with His139/Arg139 $(1,8-15)$.

Statistical analysis. Relationships between mEH overexpression and clinicopathological parameters were analyzed by Chi-Square test. When the expected number of any analysis cell was smaller than or equal to five cases, Fisher's exact test was used. To calculate the correlation of $\mathrm{mEH}$ overexpression with more than two factors, the Chi-square test for trend was used. Survival curves were plotted using the Kaplan-Meier method (24). Statistical difference in survival between the various groups was compared by the log rank test (25). Statistical significance was set at p-value 
A

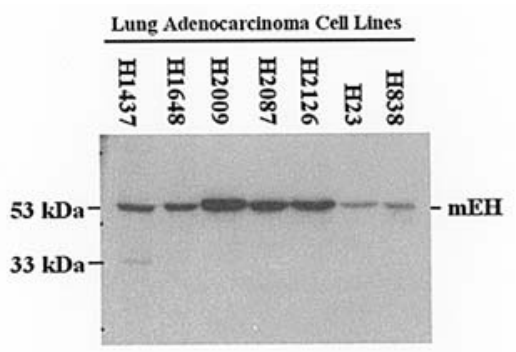

B

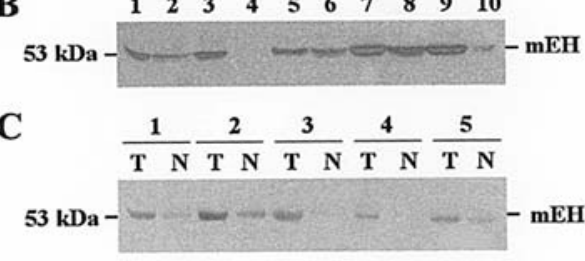

Figure 1. Overexpression of $\mathrm{mEH}$ in lung adenocarcinoma cell lines and NSCLC specimens as determined by immunoblotting. (A) Overexpression of $\mathrm{mEH}$ was detected in seven lung adenocarcinoma cell lines. The antibody mainly recognized a $53-\mathrm{kDa}$ protein. The antibody also interacted with a 33-kDa protein (lane 1). The signal however, was much weaker. (B) Overexpression of 53-kDa mEH was identified in eight out of ten human NSCLC specimens. (C) When tumor and non-tumor lung tissue were compared, the enzyme was mainly expressed in the tumor fraction. $\mathrm{N}$, non-tumor fraction of resected lung tissue; $\mathrm{T}$, tumor fraction of surgical resections.

$<0.05$. Statistical analysis was performed using GraphPad Prism4 statistical software (San Diego, CA, USA).

\section{Results}

Characterization of antibodies to $\mathrm{mEH}$ and expression of $m E H$ in NSCLC cells. Specificity of the mEH antibodies was confirmed by immunoblotting analysis which detected a single protein band $(\sim 53 \mathrm{kDa})$ present in the whole cell lysate of lung cancer cells (Fig. 1A). Moreover, overexpression of $\mathrm{mEH}$ protein was detected in eight of ten (80\%) samples (Fig. 1B). When five pairs of NSCLC specimens were compared with

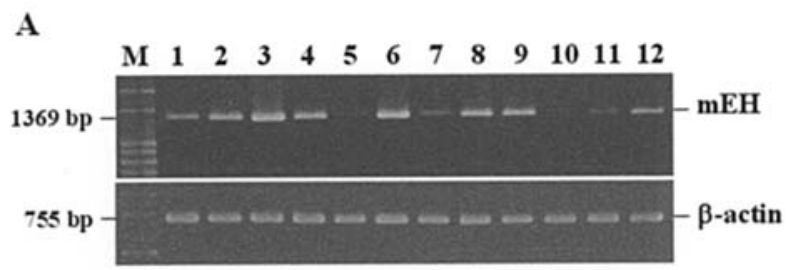

B

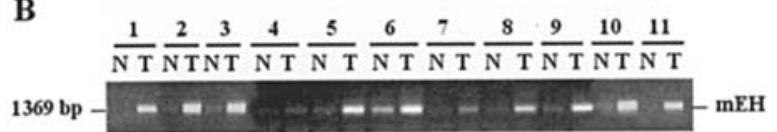

Figure 2. Expression of mEH in NSCLC detected by RT-PCR. (A) Expression of mEH mRNA (1369-bp RT-PCR product) was identified in ten out of twelve human NSCLC samples. M, DNA ladder marker. (B) When eleven pairs of NSCLC and non-tumor lung tissue were assayed, gene expression of $\mathrm{mEH}$ was mainly detected in the tumor fraction. $\mathrm{N}$, non-tumor fraction of resected lung tissue; $\mathrm{T}$, tumor fraction of surgical resections.

non-tumor fractions, $\mathrm{mEH}$ protein expression, though with various degrees, was elevated in tumor fractions (Fig. 1C). Gene expression of $\mathrm{mEH}$ was verified by RT-PCR in ten of twelve (83\%) surgical specimens (Fig. 2A). Among eleven pairs of NSCLC and non-tumor lung tissue that were assayed, gene expression of $\mathrm{mEH}$ was mainly detected in the tumor fraction (Fig. 2B). The nucleotide sequence of amplified cDNA fragments matched with the database of GenBank BC008291, Homo sapiens, epoxide hydrolase 1 and microsomal (xenobiotic).

Analyses of phenotype (allelic expression pattern), genotype and haplotype distributions. Following alignment of mRNA sequences, codon ${ }^{340} \mathrm{TAC}$ that corresponds to Tyr113 (fast type, exon 3) was detected in 65 (90.3\%) of 72 NSCLC biopsies. However, codon ${ }^{418} \mathrm{CAT}$ of exon 4 (His139, slow type) was detected exclusively in the corresponding mRNA. No ${ }^{418} \mathrm{CGT}$ (Arg139, fast type) was identified, despite that CAT/CGT heterogenotype was detected in $14(19 \%)$ of 72 samples. In

Table I. Distribution of mEH phenotypes in NSCLC patients as determined by mRNA sequences.

\begin{tabular}{|c|c|c|c|c|c|}
\hline \multirow[b]{2}{*}{ Parameter } & \multicolumn{3}{|c|}{$\begin{array}{l}\text { mEH polymorphism of codon } \\
139 \text { in exon } 4\end{array}$} & \multicolumn{2}{|c|}{$\begin{array}{l}\mathrm{mEH} \text { polymorphism of codon } \\
113 \text { in exon } 3^{\mathrm{a}}\end{array}$} \\
\hline & TAC/Tyr & $\mathrm{CAC} / \mathrm{His}$ & Odds ratio & CAT/His & CGT/Arg \\
\hline \multicolumn{6}{|l|}{ Gender } \\
\hline Male & 47 & 2 & $6.53^{\mathrm{b}}$ & 49 & 0 \\
\hline Female & 18 & 5 & & 23 & 0 \\
\hline \multicolumn{6}{|l|}{ Smoking } \\
\hline Smokers & 40 & 3 & $2.13^{\mathrm{b}}$ & 43 & 0 \\
\hline Non-smokers & 25 & 4 & & 29 & 0 \\
\hline Total percentage (\%) & 90.3 & 9.7 & & 100 & 0 \\
\hline
\end{tabular}

${ }^{a} \mathrm{p}$-value of phenotype distribution was determined by Fisher's exact test (gender, $\mathrm{p}=0.03$; smoking, $\mathrm{p}=0.428$ ). ${ }^{\mathrm{b}}$ Odds ratio of phenotype distribution was determined by Fisher's exact test. 
Table II. Distribution of mEH genotypes in NSCLC patients as determined by restriction enzyme length polymorphism of PCR products.

\begin{tabular}{|c|c|c|c|c|c|c|}
\hline \multirow[b]{2}{*}{ Parameter } & \multicolumn{3}{|c|}{$\begin{array}{c}\mathrm{mEH} \text { polymorphism of codon } \\
113 \text { in exon } 3^{\mathrm{a}}\end{array}$} & \multicolumn{3}{|c|}{$\begin{array}{c}\mathrm{mEH} \text { polymorphism of codon } \\
139 \text { in exon } 4^{\mathrm{b}}\end{array}$} \\
\hline & TAC/TAC & $\mathrm{TAC} / \mathrm{CAC}$ & $\mathrm{CAC} / \mathrm{CAC}$ & CAT/CAT & CAT/CGT & CGT/CGT \\
\hline \multicolumn{7}{|l|}{ Gender } \\
\hline Male & 20 & 27 & 2 & 38 & 11 & 0 \\
\hline Female & 8 & 12 & 3 & 20 & 3 & 0 \\
\hline \multicolumn{7}{|l|}{ Smoking } \\
\hline Smokers & 15 & 26 & 2 & 31 & 12 & 0 \\
\hline Non-smokers & 13 & 13 & 3 & 27 & 2 & 0 \\
\hline Total percentage $(\%)$ & 44.4 & 48.6 & 7.0 & 80.6 & 19.4 & 0 \\
\hline
\end{tabular}

${ }^{\mathrm{a}} \mathrm{p}$-value of genotype distribution of codon 113 polymorphism was determined by the Pearson $\chi^{2}$ test (gender, $\mathrm{p}=0.371 ; \mathrm{smoking}, \mathrm{p}=0.510$ ). ${ }^{\mathrm{b}} \mathrm{p}$-value of genotype distribution of codon 139 polymorphism was determined by Fisher's exact test (gender, $\mathrm{p}=0.525$; odds ratio =1.93; smoking, $\mathrm{p}=0.035$; odds ratio $=5.22$ ).
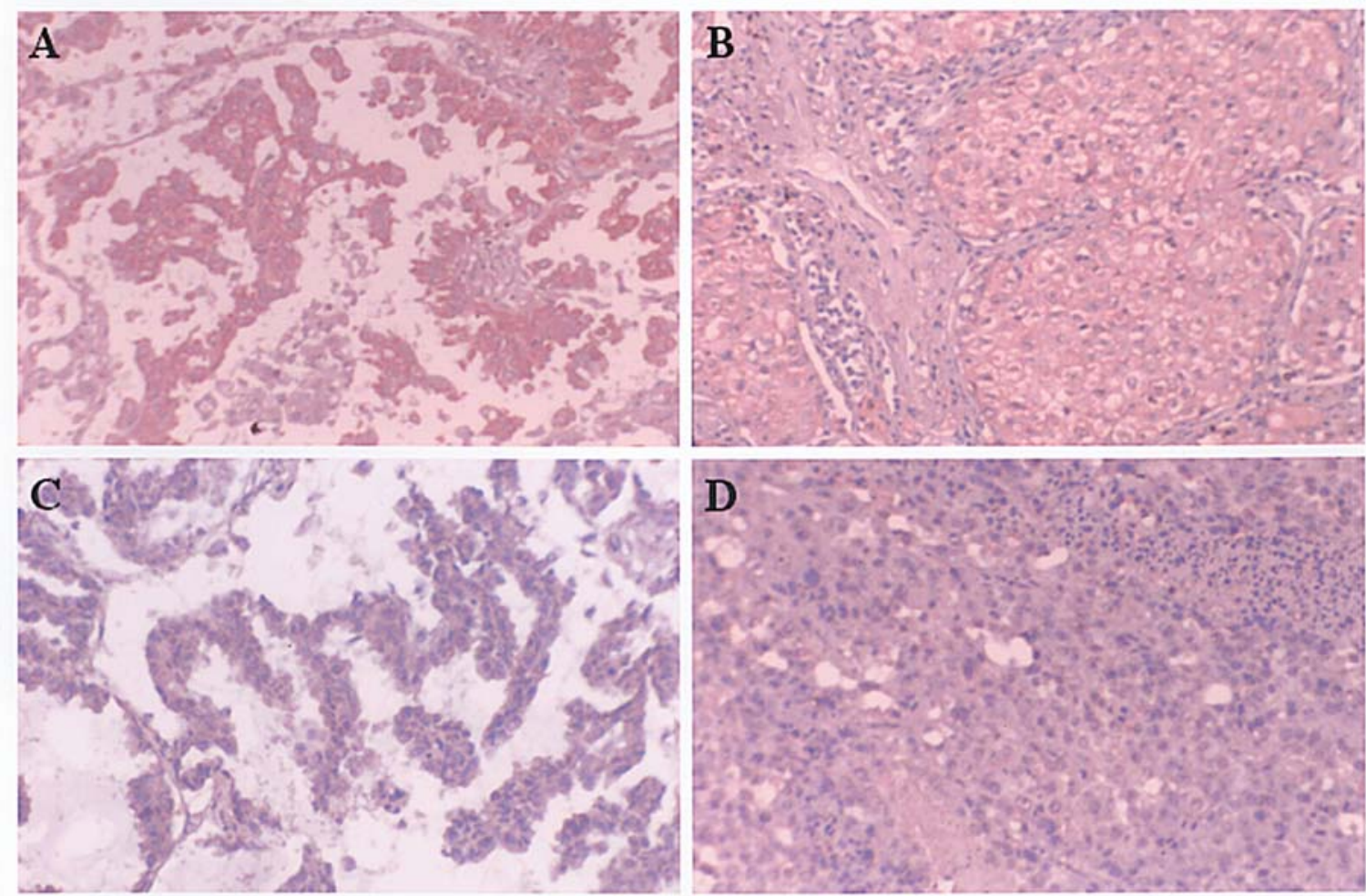

Figure 3. Representative examples of mEH overexpression. (A) Adenocarcinoma. (B) Squamous cell carcinoma of NSCLC detected by immunohistochemical staining. (C) Adenocarcinoma cells. (D) Squamous cell carcinoma of NSCLC that did not express mEH. Expression of mEH was not detected in the normal stroma (original magnification x200).

order to eliminate the possibility of preferential selection of cDNA, sequences of PCR product and four other clones from these 14 samples were repeatedly determined, and the result remained negative for Arg139/CGT phenotype (Table I). Interestingly, when a smoking habit with a cut-off value of 20 pack-years (10), was included for evaluating the gene expression pattern, the predominant $\mathrm{mEH}$ phenotype expressed in patients with His/Argexon 4 heterogenotype was His139exon 4 (Table II, $\mathrm{p}=0.035$ ), and the male patients $(96 \%)$ were more prone to express fast-type $\mathrm{mEH}$ than the female patients $(78 \%)(p=0.03)$. The difference was not statistically significant when haplotype was used as a determinant. Distributions of phenotype (cDNA sequences), and genotype (genomic DNA sequences) are respectively summarized in Tables I and II. 
Table III. Comparison of clinicopathological parameters between patients with and without mEH overexpression.

\begin{tabular}{|c|c|c|c|c|c|}
\hline \multirow[b]{2}{*}{ Parameter } & \multicolumn{2}{|c|}{ mEH overexpression } & \multirow[b]{2}{*}{ p-value } & \multirow[b]{2}{*}{$95 \%$ confidence interval } & \multirow{2}{*}{$\begin{array}{l}\text { Odds ratio or or } \\
\text { likelihood ratiof }\end{array}$} \\
\hline & Positive $(n=326)$ & Negative $(n=97)$ & & & \\
\hline Age (years) & $66.3 \pm 7.8$ & $56.8 \pm 9.2$ & $<0.001^{\mathrm{a}}$ & & \\
\hline \multicolumn{6}{|l|}{ Gender } \\
\hline Male $(n=323)$ & 254 & 69 & $0.168^{\mathrm{b}}$ & 0.858 to $2.387^{\mathrm{d}}$ & $1.432^{\mathrm{e}}$ \\
\hline Female $(n=100)$ & 72 & 28 & & & \\
\hline \multicolumn{6}{|l|}{ Smoking } \\
\hline Smokers $(\mathrm{n}=276)$ & 244 & 32 & $<0.001^{\mathrm{b}}$ & 3.654 to $9.759^{\mathrm{d}}$ & $5.971^{\mathrm{e}}$ \\
\hline Non-smokers $(\mathrm{n}=147)$ & 82 & 65 & & & \\
\hline Mitotic index (\#/10 HPF) & $5.5 \pm 4.3$ & $5.1 \pm 4.7$ & $0.32^{\mathrm{a}}$ & & \\
\hline \multicolumn{6}{|l|}{ Tumor type } \\
\hline $\operatorname{SCC}(n=225)$ & 162 & 63 & $0.008^{\mathrm{b}}$ & & $10.222^{\mathrm{f}}$ \\
\hline $\mathrm{AD}(\mathrm{n}=147)$ & 126 & 21 & & & \\
\hline Mixed $(n=51)$ & 38 & 13 & & & \\
\hline \multicolumn{6}{|l|}{ Stage } \\
\hline $\mathrm{I}(\mathrm{n}=170)$ & 118 & 52 & $0.001^{\mathrm{c}}$ & & $20.342^{\mathrm{f}}$ \\
\hline IIa $(n=42)$ & 31 & 11 & & & \\
\hline $\mathrm{IIb}(\mathrm{n}=112)$ & 88 & 24 & & & \\
\hline IIIa $(n=41)$ & 35 & 6 & & & \\
\hline IIIb $(n=45)$ & 41 & 4 & & & \\
\hline IV (n=13) & 13 & 0 & & & \\
\hline \multicolumn{6}{|l|}{ Cell differentiation } \\
\hline Well $(n=63)$ & 38 & 25 & $0.776^{\mathrm{c}}$ & & $0.507^{\mathrm{f}}$ \\
\hline Moderate $(n=265)$ & 153 & 112 & & & \\
\hline Poor $(n=95)$ & 52 & 43 & & & \\
\hline \multicolumn{6}{|l|}{ Lymphovascular invasion } \\
\hline Positive $(\mathrm{n}=253)$ & 186 & 47 & $0.135^{\mathrm{b}}$ & 0.897 to $2.227^{\mathrm{d}}$ & $1.413^{\mathrm{e}}$ \\
\hline Negative $(n=170)$ & 140 & 50 & & & \\
\hline \multicolumn{6}{|l|}{ DDH } \\
\hline Positive $(n=362)$ & 297 & 65 & $<0.001^{\mathrm{b}}$ & 2.852 to $8.914^{\mathrm{d}}$ & $5.043^{\mathrm{e}}$ \\
\hline Negative $(n=61)$ & 29 & 32 & & & \\
\hline
\end{tabular}

${ }^{a}$ Two-sided p-value determined by t-test. ${ }^{b}$ Two-sided p-value determined by the Pearson $\chi^{2}$ test. ${ }^{\mathrm{c}} \mathrm{Chi}$-square test for trend. ${ }^{\mathrm{d}} 95 \%$ confidence

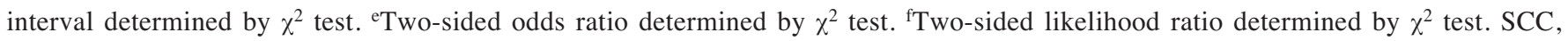
squamous cell carcinoma; AD, adenocarcinoma; HPF, high power field.

Clinical significance of $m E H$ overexpression in NSCLC patients. Among the 452 patients, 29 deaths were surgeryrelated (12 patients died of sepsis and 17 of cardiopulmonary failure). The median follow-up time for the remaining 423 patients was 26 months, ranging from 2.0 to 109 months. The mean age of the patients was 64.1 years, ranging from 27 to 87 years. In this study, 323 men and 100 women were enrolled, and 276 patients $(65.2 \%)$ were smokers. Following surgery, 180 patients showed evidence of tumor recurrence. Positive $\mathrm{mEH}$ overexpression was identified when the tumor fraction expressed a higher level of $\mathrm{mEH}$ than the non-tumor fraction of resected lung tissue. As shown in Table III, no significant difference was found between $\mathrm{mEH}$ overexpression and patient gender, cell differentiation patterns, tumor type or histopathological features (mitotic index and evidence of lymphovascular invasion). Statistical differences however, were found between $\mathrm{mEH}$ overexpression and age $(\mathrm{p}<0.001)$, smoking habit $(\mathrm{p}<0.001)$, stages $(\mathrm{p}=0.001)$ and dihydrodiol dehydrogenase $(\mathrm{DDH})$ expression $(\mathrm{p}<0.001)$. Interestingly, male patients also had a significantly higher incidence of $\mathrm{mEH}$ expression and tumor recurrence than female patients $(\mathrm{p}<0.005)$. 
$\mathbf{A}$

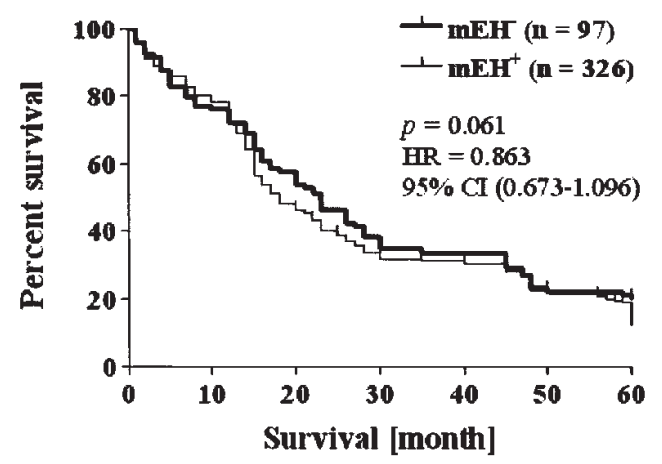

B

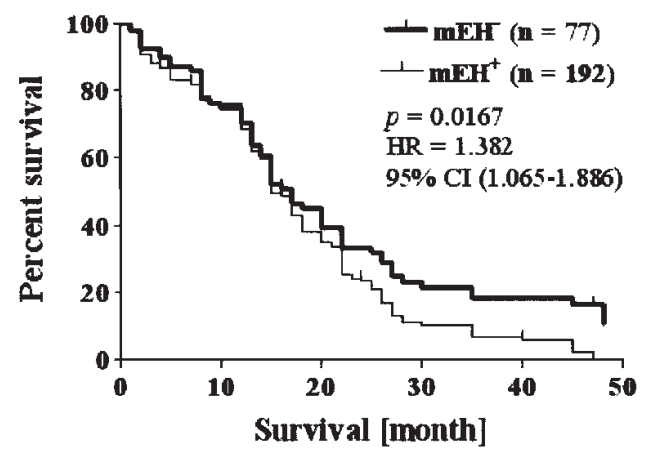

Figure 4. Cumulative survival curves in patients with NSCLC. Survival curves were plotted with the Kaplan and Meier method. Statistical difference of survival between two groups was compared by a log rank test. (A) A marginal difference in total survival rate was found between patients divided by $\mathrm{mEH}$ expression (mEH-negative, $\mathrm{n}=97$; $\mathrm{mEH}$-positive, $\mathrm{n}=326)(\mathrm{p}=0.061)$. (B) However, when only patients who received chemotherapy containing doxorubicin were analyzed according to $\mathrm{mEH}$ expression ( $\mathrm{mEH}$-negative, $\mathrm{n}=77$; mEH-positive, $\mathrm{n}=192$ ), the difference of cumulative survival was significant $(\mathrm{p}=0.0167)$.

As determined by immunohistochemistry, 326 (77.0\%) of 423 patients overexpressed mEH (Fig. 3A and B), and 97 (23.0\%) were $\mathrm{mEH}$-negative (Fig. 3C and D). Overexpression of $\mathrm{mEH}$ was also detected in $51.6 \%$ (48/93) of metastatic lymph nodes. Among $326 \mathrm{mEH}$-positive $\left(\mathrm{mEH}^{+}\right)$patients, $142(43.6 \%)$ had tumor recurrences, and among $97 \mathrm{mEH}-$ negative (mEH) patients, only 38 (39.1\%) developed metastatic lesions. The difference however, was marginal $(\mathrm{p}=0.058)$. When $\mathrm{mEH}$ overexpression was used to divide patient groups $\left(\mathrm{mEH}+\mathrm{n}=97\right.$; and $\left.\mathrm{mEH}^{+}, \mathrm{n}=326\right)$, a marginal difference was found in total survival ( $\mathrm{p}=0.061$, Fig. 4A). When only patients who had received adjuvant chemotherapy containing doxorubicin were investigated, the survival of $\mathrm{mEH}^{+}$patients $(\mathrm{n}=192)$ was significantly worse than that of $\mathrm{mEH}^{-}$patients $(n=77)$ $(\mathrm{p}=0.0167$, Fig. 4B).

\section{Discussion}

The results presented above showed that the major form of $\mathrm{mEH}$ expressed in NSCLC is the fast type (Tyr113) in exon 3 $(90.3 \%)$ and the slow type (His139) in exon 4 (100\%). In combination, these types constituted an $\mathrm{mEH}$ with intermediate activity. Clinically, $\mathrm{mEH}$ overexpression in cancer cells was correlated inversely with patient survival, in particular in patients who received adjuvant chemotherapy containing doxorubicin and cisplatin. Patients with $\mathrm{mEH}$ overexpression had significantly poorer prognosis.

Previous studies by several groups provided invaluable data on genotypic polymorphism in various cancers including lung cancer, and indicated that a detection rate of ${ }^{340} \mathrm{TAC}$ allele (Tyr113) in exon 3 ranged from 0.63 to 0.77 , and that of ${ }^{418}$ CAT (His139) in exon 4 ranged from 0.77 to 0.94 (10-15). Our results agreed with their findings, and show that genotype distributions of $\mathrm{mEH}$ in Taiwan's NSCLC patients were $44.4 \%$ of ${ }^{340} \mathrm{TAC} /{ }^{340} \mathrm{TAC}, 48.6 \%$ of ${ }^{340} \mathrm{TAC} /{ }^{340} \mathrm{CAC}$, and $7.0 \%$ of ${ }^{340} \mathrm{CAC} /{ }^{340} \mathrm{CAC}$ in exon 3 , and $80.6 \%$ of ${ }^{418} \mathrm{CAT} /{ }^{418} \mathrm{CAT}$, $19.4 \%$ of ${ }^{418} \mathrm{CAT} /{ }^{418} \mathrm{CGT}$ and $0 \%$ of ${ }^{418} \mathrm{CGT} /{ }^{418} \mathrm{CGT}$ in exon 4 . In contrast, phenotype distributions were $90.3 \%$ of intermediate (Tyr113 exon 3/His $139^{\text {exon } 4}$ ) and $9.7 \%$ of low (His $113^{\text {exon } 3 /}$ His $139^{\text {exon }} 4$ ) activity variants (Table I). Even in patients with ${ }^{418} \mathrm{CAT} /{ }^{118} \mathrm{CGT}^{\mathrm{exon}}{ }^{4}$ heterogenotype, phenotype was mainly His $139^{\text {exon } 4}$ (Tables I and II). A parallel study on normal population would help to determine whether the imbalanced allelic expression of $\mathrm{mEH}$ observed in NSCLC patients is disease-related. However, it may be difficult to obtain lung tissue from normal population. It is interesting to note that phenotype distribution between men and women was significantly different $(\mathrm{p}=0.03)$, and most male patients expressed Tyr113.

In a large population study, Zhou et al (10) raised a controversial issue that although passive cigarette smoking could increase lung cancer risk in non-smokers, cumulative cigarette smoking, on the other hand, could fortuitously protect heavy smokers from lung carcinogenesis. In a mutagenesis study, Hasset et al (8) suggested that the protection effect could be due to the 'allelic selection' of gene expression. By showing that high activity $\mathrm{mEH}$ with $\operatorname{Tyr} 113^{\text {exon } 3 / \operatorname{Arg} 139^{\text {exon }} 4}$ was barely detected in NSCLC patients, our results indicated that selection pressure could be from air pollution, in particular, cigarette smoking or heavy oil fumes from the traditional Chinese cooking method (such as frying fish) (26). Several studies supported such a point of view by demonstrating that in addition to genetic predisposition, the activity and stability of PAH metabolism-associated enzymes, e.g. $\mathrm{mEH}$, glutathione-S-transferase (GST), N-acetyltransferase-2, and Cyp1A1, are also critical in cellular response to mutagen(s) or carcinogen(s), which are closely associated with lung cancer risk (11,27-32).

By measuring the conversion activity of the S-12 fraction from lung peripheral parenchyma, Petruzzelli et al demonstrated that normal lung epithelial cells were not capable of metabolizing PAH (33). By immunohistochemical staining, Coller et al indicated that the incapability to catabolize PAH could result from the lack of GST, aryl hydrocarbon hydroxylase and $\mathrm{mEH}$ (5). These two groups further suggested that pulmonary carcinogenesis might be directly mediated by PAH conjugates, e.g., benzo(a)pyrenated serum albumin, instead of PAH per se, which had to be activated in other organs, such as liver and kidney $(5,6)$. Moreover, minute particles of cigarette smoking could also induce $\mathrm{mEH}$ expression and local pulmonary inflammation. The increased $\mathrm{mEH}$ and PAH metabolites could aggravate the damage to 
lung epithelium, and activate regeneration of pulmonary epithelial cells to repair respiratory function. Growth factor(s) produced during repair might conversely facilitate disease progression of NSCLC.

Besides lung cancer, by examining antiestrogen binding activity, Fritz et al demonstrated that $\mathrm{mEH}$ expression could also be an important index for tamoxifen resistance, which was closely associated with poor prognosis, in primary breast cancer (18). By showing a similar correlation between survival and $\mathrm{mEH}$ expression in NSCLC patients, in particular, in those who had received regimens containing doxorubicin, our data not only supported their findings, but also suggested that involvement of $\mathrm{mEH}$ in drug resistance of cancer cells could be general. In this study, mEH overexpression in NSCLC patients was associated significantly with DDH expression $(\mathrm{p}<0.001)$ (Table III). It is worth noting that expression of $\mathrm{DDH}$, an essential enzyme for catalyzing epoxide hydrolasemediated formation of epoxide, was also associated with cisplatin-related drug resistance in ovarian cancer cells (34). The role of $\mathrm{mEH}$ as well as the involvement of DDH in drug resistance are currently being evaluated in an ongoing in vitro study.

In conclusion, our results showed that $\mathrm{mEH}$ overexpression was frequently detected in the pathologic specimens of NSCLC patients and correlated with tumor stages. The majority of $\mathrm{mEH}$ detected are the fast type (Tyr113) in exon 3 and the slow type (His139) in exon 4. With this combination, the enzyme has intermediate enzyme activity. Although the prognosis of patients with $\mathrm{mEH}$ overexpression in NSCLC cancer cells was generally poor, especially in those who had received regimens containing anthracycline and cisplatin, the clinical association of increased $\mathrm{mEH}$ expression with disease progression, however, remains to be determined.

\section{Acknowledgments}

We thank Ms. Chih-Yo Kuan and Ting-Yu Lin for technical assistance, and Ms. Ya-Hue Chen for collecting the clinical data. This study was supported in part by the National Science Council (NSC92-2320-B-005-011), Taiwan, Republic of China.

\section{References}

1. Miyata M, Kudo G, Lee YH, et al: Targeted disruption on the microsomal epoxide hydrolase gene. J Biol Chem 274: 23963-23968, 1999.

2. Kuljukka-Rabb T, Nylund L, Vaaranrinta R, et al: The effect of relevant genotypes on PAH exposure-related biomarker. J Expo Anal Environ Epidemiol 12: 81-91, 2002.

3. Kelly EJ, Erickson KE, Sengstag C and Eaton DL: Expression of human microsomal epoxide hydrolase in Saccharomyces cerevisiae reveals a functional role in aflatoxin B1 detoxification. Toxicol Sci 65: 35-42, 2002.

4. To-Figueras J, Gene M, Gomez-Catalan J, Pique E, Borrego N and Corbella J: Lung cancer susceptibility in relation to combined polymorphisms of microsomal epoxide hydrolase and glutathione S-transferase P1. Cancer Lett 173: 155-162, 2001 .

5. Coller JK, Fritz P, Zanger UM, et al: Distribution of microsomal epoxide hydrolase in humans: an immunohistochemical study in normal tissues, and benign and malignant tumors. Histochem J 33: 329-336, 2001.

6. Ota K and Hammock BD: Cytosolic and microsomal epoxide hydrolases: differential properties in mammalian liver. Science 207: 1479-1481, 1980 .
7. El-Tantawy MA and Hammock BD: The effect of hepatic microsomal and cytosolic subcellular fractions on the mutagenic activity of epoxide-containing compounds in the Salmonella assay. Mutat Res 79: 59-71, 1980.

8. Hassett C, Aicher L, Sidhu JS and Omiecinski CJ: Human microsomal epoxide hydrolase: genetic polymorphism and functional expression in vitro of amino acid variants. Hum Mol Genet 3: 421-428, 1994.

9. Rodriguez F, Jardi R, Costa X, et al: Detection of polymorphisms at exon 3 (Tyr113 $\rightarrow$ His) and 4 (His $139 \rightarrow$ Arg) of the microsomal epoxide hydrolase gene using fluorescence PCR method combined with melting curves analysis. Anal Biochem 308: 120-126, 2002.

10. Zhou W, Liu G and Thurston SW, et al: Genetic polymorphisms in $\mathrm{N}$-acetyltransferase- 2 and microsomal epoxide hydrolase, cumulative cigarette smoking, and lung cancer. Cancer Epidemiol Biomarkers Prev 11: 15-21, 2002.

11. Lee WJ, Brennan P, Boffetta P, et al: Microsomal epoxide hydrolase polymorphisms and lung cancer risk: a quantitative review. Biomarkers 7: 230-241, 2002.

12. Williams JA and Phillips DH: Mammary expression of xenobiotic metabolizing enzymes and their potential role in breast cancer. Cancer Res 60: 4667-4677, 2000.

13. Cortessis V, Siegmund K, Chen Q, et al: A case-control study of microsomal epoxide hydrolase, smoking, meat consumption, glutathion S-transferase M3, and risk of colorectal adenomas. Cancer Res 61: 2381-2385, 2001.

14. Jourenkova-Mironova N, Mitrunen K, Bouchardy C, Dayer P, Benhamou S and Hirvonen A: High-activity microsomal epoxide hydrolase genotypes and the risk of oral, pharynx, and larynx cancers. Cancer Res 60: 534-536, 2000.

15. To-Figueras J, Gene M, Gomez-Catalan J, et al: Microsomal epoxide hydrolase and glutathione S-transferase polymorphisms in relation to laryngeal carcinoma risk. Cancer Lett 187: 95-101, 2002.

16. Salama SA, Sierra-Torres CH, Oh HY, Hamada FA and Au WW: Variant metabolizing gene alleles determine the genotoxicity of benzo[a]pyrene. Environ Mol Mutagen 37: 17-26, 2001.

17. Pastorelli R, Guanci M, Cerri A, et al: Impact of inherited polymorphisms in glutathione S-transferase M1, microsomal epoxide hydrolase, cytochrome P450 enzymes on DNA, and blood protein adducts of benzo(a)pyrene-diolepoxide. Cancer Epidemiol Biomarkers Prev 7: 703-709, 1998.

18. Fritz P, Murdter TE, Eichelbaum M, Siegle I, Weissert M and Zanger UM: Microsomal epoxide hydrolase expression as a predictor of tamoxifen response in primary breast cancer: a retrospective exploratory study with long-term follow-up. J Clin Oncol 19: 3-9, 2001.

19. Keicho N, Emi M, Kajita M, et al: Overestimated frequency of a possible emphysema-susceptibility allele when microsomal epoxide hydrolase is genotyped by the conventional polymerase chain reaction-based method. J Hum Genet 46: 96-98, 2001.

20. Green VJ, Pirmohamed M, Kitteringham NR, et al: Genetic analysis of microsomal epoxide hydrolase in patients with carbamazepine hypersensitivity. Biochem Pharmacol 50: 1353-1359, 1995.

21. Tsai CM, Chang KT, Chen JY, Chen YM, Chen MH and Perng RP: Cytotoxic effects of gemcitabine-containing regimens against human non-small cell lung cancer cell lines which express different levels of p185neu. Cancer Res 56: 794-801, 1996.

22. Chow KC and Ross WE: Topoisomerase specific drug sensitivity in relation to cell cycle progression. Mol Cell Biol 7: 3119-3123, 1987

23. Chiou CF, Chow KC, Lin FM, Lin CK, Liu SM and Chen KY: Expression of DNA topoisomerase II $\alpha$ and multidrug resistance p-glycoprotein in acute leukemia - an immunohistochemical study. Chin Med J 60: 184-190, 1997.

24. Kaplan EL and Meier P: Nonparametric estimation from incomplete observations. J Am Stat Assoc 53: 457-481, 1958.

25. Mantel N: Evaluation of survival data and two new rank order statistics arising in its consideration. Cancer Chemother Rep 50: 163-170, 1996.

26. Chiang TA, Wu PF, Wang LF, Lee H, Lee CH and Ko YC: Mutagenicity and polycyclic aromatic hydrocarbon content of fumes from heated cooking oils produced in Taiwan. Mutat Res 381: 157-161, 1997.

27. Benhamou S, Reinikainen M, Bouchardy C, Dayer P and Hirvonen A: Association between lung cancer and microsomal epoxide hydrolase genotypes. Cancer Res 58: 5291-5293, 1998. 
28. Harris CC, Weston A, Willey JC, Trivers GE and Mann DL: Biochemical and molecular epidemiology of human cancer: indicators of carcinogen exposure, DNA damage, and genetic predisposition. Environ Health Perspect 75: 109-119, 1987.

29. Fryer AA and Jones PW: Interactions between detoxifying enzyme polymorphisms and susceptibility to cancer. IARC Sci Publ 148: 303-322, 1999.

30. Kiyohara C, Otsu A, Shirakawa T, Fukuda S and Hopkin JM: Genetic polymorphisms and lung cancer susceptibility: a review. Lung Cancer 37: 241-256, 2002.

31. Zhang JH, Jin X, Li Y, et al: Epoxide hydrolase Tyr113His polymorphism is not associated with susceptibility to esophageal squamous cell carcinoma in population of North China. World J Gastroenterol 9: 2654-2657, 2003.
32. De Assis S, Ambrosone CB, Wustrack S, Krishnan S, Freudenheim JL and Shields PG: Microsomal epoxide hydrolase variants are not associated with risk of breast cancer. Cancer Epidemiol Biomarkers Prev 11: 1697-1698, 2002.

33. Petruzzelli S, de Flora S, Bagnasco M, et al: Carcinogen metabolism studies in human bronchial and lung parenchymal tissues. Am Rev Respir Dis 140: 417-422, 1989.

34. Deng HB, Parekh HK, Chow KC and Simpkins H: Increased expression of dihydrodiol dehydrogenase induces resistance to cisplatin in human ovarian carcinoma cells. J Biol Chem 277: 15035-15043, 2002. 